\title{
Synergistic antitumor effect of BRMS1 and sorafenib via inhibition of the PI3K/AKT/mTOR/ERK signaling pathway
}

\author{
JINGYUN JIN ${ }^{1,2^{*}}$, YONGGANG GUO ${ }^{3,4^{*}}$, YANG LIU $^{5 *}$, ZHENGUO WANG $^{1,2}$, \\ XIAOSA YANG ${ }^{6,7}$ and SHENGKAI SUN ${ }^{1,2}$
}

${ }^{1}$ Department of Medicine and Scientific Research, Characteristic Medical Center of The Chinese People's Armed Police Force; ${ }^{2}$ Department of Medicine and Scientific Research, Pingjin Hospital; ${ }^{3}$ Department of General Surgery Department,

Characteristic Medical Center of The Chinese People's Armed Police Force; ${ }^{4}$ Department of General Surgery,

Pingjin Hospital, Tianjin 300162; ${ }^{5}$ Department of Neurology, Central Hospital of Minhang, Shanghai 200000;

${ }^{6}$ Department of Brain, Characteristic Medical Center of The Chinese People's Armed Police Force;

${ }^{7}$ Department of Brain, Pingjin Hospital, Tianjin 300162, P.R. China

Received January 22, 2019; Accepted May 23, 2019

DOI: 10.3892/or.2019.7210

\begin{abstract}
Liver cancer is the fifth most commonly occurring cancer in men and the ninth most commonly occurring cancer in women, worldwide, and is associated with a high mortality rate. Sorafenib is a new inhibitor of multiple kinases, that is regarded as standard treatment for liver cancer. Human breast carcinoma metastasis-suppressor 1 (BRMS1) is a tumor-suppressor gene, that reduces the metastatic ability of tumor cells without affecting their tumorigenicity. In the present study, a model of BRMS1 overexpression and BRMS1 knockdown was established in HepG2 cells. The results revealed that the proliferation of HepG2 cells was inhibited in response to sorafenib treatment using MTT assay. Furthermore, BRMS1 overexpression enhanced the effect of sorafenib. In addition, expression of inflammatory response-related genes
\end{abstract}

Correspondence to: Dr Xiaosa Yang, Department of Brain, Characteristic Medical Center of The Chinese People's Armed Police Force, 220 Chenglin Road, Tianjin 300162, P.R. China E-mail: 554718383@qq.com

Dr Shengkai Sun, Department of Medicine and Scientific Research, Pingjin Hospital, 220 Chenglin Road, Tianjin 300162, P.R. China

E-mail: shengkai_sun2018@163.com

*Contributed equally

Abbreviations: BRMS1, breast carcinoma metastasis-suppressor 1; PI3K, phosphatidylinositol 3-kinase; AKT, PKB protein kinase; mTOR, mammalian target of rapamycin; ERK, extracellular signal-regulated kinase; qPCR, real-time quantitative polymerase chain reaction; IGF, insulin-like growth factor; TNF- $\alpha$, tumor necrosis factor- $\alpha$; VEGF, vascular endothelial growth factor; EGF, epidermal growth factor

Key words: BRMS1, liver cancer cells, sorafenib, antitumor effect, $\mathrm{PI} 3 \mathrm{~K} / \mathrm{AKT} / \mathrm{mTOR} / \mathrm{ERK}$ signaling pathway was increased, while secretion of angiogenesis-related molecules was decreased, and apoptosis was also activated after sorafenib treatment using qPCR method, and it was further demonstrated that this effect was mediated by inhibition of the $\mathrm{PI} 3 \mathrm{~K} / \mathrm{AKT} / \mathrm{mTOR} / \mathrm{ERK}$ signaling pathway using western blot analysis. In conclusion, overexpression of BRMS1 potentiated the effect of sorafenib via PI3K/AKT/mTOR/ERK signaling, while knockdown of BRMS1 expression attenuated this effect. These findings may present a novel therapeutic strategy for liver cancer.

\section{Introduction}

Liver cancer is the fifth most commonly occurring cancer in men and the ninth most commonly occurring cancer in women, worldwide, ranking third in cancer-related mortality (1). Standard management of liver cancer includes surgery, chemotherapy and radiation therapy, which are dependent upon tumor stage, liver function and patient performance (2). Sorafenib is an oral inhibitor of multiple kinases, and is the standard treatment for patients with liver cancer (3). Sorafenib inhibits expression of several tyrosine kinases that are critical for angiogenesis and tumor progression, including vascular endothelial growth factor receptor (VEGFR)-2/3, platelet-derived growth factor receptor (PDGF-R) and Raf kinases involved in the MAPK/ERK pathway (4). Human breast carcinoma metastasis-suppressor 1 (BRMS1) gene was first discovered over a decade ago, and was found to reduce the metastatic capacity of MDA-MB-435 human breast carcinoma cells by $70-90 \%$ without affecting tumorigenicity (5). Another study found that the metastatic potential of MDA-MB-435 cells stably transfected with BRMS1 to the lungs and regional lymph nodes was significantly reduced (50-90\% inhibition) (6). In addition, hypermethylation is consistently found in the promoter region of BRMS1 in malignant tumor cells, indicating that decreased BRMS1 expression may be a clinical biomarker of malignant tumors. Multiple patient tissues with lymph node metastases were found to have hypermethylated $\mathrm{CpG}$ island of the BRMS1 gene (7). A previous 
study found hypermethylation in $60 \%$ of lymph node metastases and in $45 \%$ of primary tumors, suggesting that methylation is related to tumor development and progression (8). A recent study identified hypermethylation of the BRMS1 promoter region in tumor cells isolated from peripheral blood of breast cancer patients when compared to healthy controls (9). Another study found that loss of BRMS1 was associated with reduced disease-free survival when patient samples were stratified by loss of the estrogen receptor (ER) or the progesterone receptor (PR) or by expression of HER2 (10).

In the present study, BRMS1 overexpression and knockdown models were initially established in HepG2 cells. It was demonstrated that overexpression of BRMS1 significantly increased the inhibitory effect of sorafenib on cell proliferation when compared to that noted in the controls, while knockdown of BRMS1 attenuated this effect. Sorafenib was also found to induce the apoptosis of HepG2 cells. In addition, expression of inflammatory response-related genes was increased, while secretion of angiogenesis-related molecules was decreased, in response to sorafenib treatment. We further demonstrated that these effects on tumor cells might be mediated by inhibition of the PI3K/AKT/mTOR/ERK signaling pathway. Overexpression of BRMS1 potentiated the treatment effect of sorafenib and knockdown of BRMS1 attenuated these effects. Therefore, overexpression of BRMS1 synergistically enhanced the therapeutic effect of sorafenib on liver cancer and may represent a novel therapeutic strategy.

\section{Materials and methods}

Materials. Fetal bovine serum (FBS) (MF191-01) and high glucose Dulbecco's modified Eagle's medium (H-DMEM) (MF219-01) were purchased from Mei5 Biotechnology Co., Ltd. (Beijing, China). MTT Cell Proliferation and Cytotoxicity Assay kit (M1020), Lip2000 transfection reagent (L7800) and G418 (G8160) were purchased from Solarbio (Beijing, China). HindIII (R0104L), EcoRI (R0101L), Quick Ligase (M2200S) and T4 PNK (M0201S) were purchased from New England Biolabs, Inc. (NEB; Ipswich, MA, USA). FastDigest BsmBI (FD0454) was purchased from Fermentas (Thermo Fisher Scientific, Inc.). Protease inhibitor cocktail (CW2200), phosphatase inhibitor cocktail (CW2383), Ultrapure RNA kit (CW0597) and Super TaqMan OneStep RT-qPCR kit (CW2695) were purchased from CWbio Biological Technology Company (Beijing, China). TRITC phalloidin (40734ES75), DAPI stain solution (40728ES03) and PI staining solution (40755ES64) were purchased from Yeasen Biotechnology Co. (Shanghai, China). Anti-BRMS1 (ab180852), p-AKT (ab38449), AKT (ab179463), p-mTOR (ab137133), mTOR (ab134903), p-ERK (ab50011), ERK (ab17942), p-BIM (ab17935), BIM (ab32158), p-PTEN (ab109454), PTEN (ab32199), Bax (ab32503), Bcl-2 (ab196495), TNF- $\alpha$ (ab109322), caspase-9 (ab52298), caspase-3 (ab13847) antibodies and human IGF1 (ab211651), TGF- $\beta$ (ab100647) and VEGF (ab100662) ELISA kits were purchased from Abcam (Cambridge, UK). Sorafenib (BAY 43-9006) was purchased from Enzo Life Science (Farmingdale, NY, USA). HepG2 cells (TCHu 72) and 293T cells (SCSP-502) were purchased from the Cell Library of the Typical Culture Preservation Committee of the Chinese Academy of Sciences.
Vector construction. The cDNA of BRMS1 was cloned from cells using PCR methods using the following primers: Forward, 5'-ATCGAAGCTTACTATGCCTGTCCAGCCTCC AAGC-3' and reverse, 5'-ATGCGAATTCTCAAGGTCCAT CCGATTC-3'. Blank pCNDA3.1 vector and PCR product of BRMS1 were digested with HindIII and EcoRI, and the BRMS1 fragment was cloned into the vector to construct the pCDNA3.1-BRMS1 overexpression vector. HepG2 cells were transfected with pCDNA3.1-BRMS1 and pcDNA3.1 blank vector using Lip2000 transfection reagent for $48 \mathrm{~h}$ according to the manufacturer's protocol. Stable BRMS1 overexpression cells and blank vector cells were screened using $800 \mu \mathrm{g} / \mathrm{ml} \mathrm{G} 418$. The BRSM1 knockdown vector was constructed according to a previous study (11). Briefly, the CRISPR vector was firstly digested with BsmBI according to the protocol, and annealed oligos were constructed using the following primers: Forward, 5'-CACCGCTACACAGTG CAATTGCCTCC-3' and reverse, 5'-AAACGATGTGTCACG TTAACGGAGC-3'. Ligation reactions were subsequently performed using annealed oligos and digested CRISPR vector according to the Quick Ligase protocol to construct the BRSM1 knockdown vector. Stable BRMS1 knockdown cells were screened using $2 \mu \mathrm{g} / \mathrm{ml}$ puromycin.

Cell culture and experimental groups. Cells were cultured in a humidified atmosphere supplied with $5 \% \mathrm{CO}_{2}$ at $37^{\circ} \mathrm{C}$ with $\mathrm{H}-\mathrm{DMEM}$ and $10 \% \mathrm{FBS}$. Cells were divided into four groups: Controls (NC), sorafenib treatment (ST), sorafenib treatment with BRMS1 overexpression (BO) and sorafenib treatment with BRMS1 knockdown (BD). The concentration and treatment period for sorafenib used in this experiment $(10 \mu \mathrm{M}$ for $24 \mathrm{~h}$ ) was determined according to a previous study (12).

Cellular proliferation assay. MTT assay was performed according to the protocol of MTT Cell Proliferation and Cytotoxicity Assay kit. Briefly, cells were firstly cultured and grouped as previously described, seeded into a 96-well plate at a concentration of $1 \times 10^{4}$ cells/well, and cultured until cell confluence reached $80-85 \%$. Then, the cells were incubated with $5 \mathrm{mg} / \mathrm{ml}$ MTT reagent for $4 \mathrm{~h}$ after washing with phosphate-buffered saline (PBS), and optical density (OD) values were determined at $560 \mathrm{~nm}$ using the SuPerMax 3100 microplate reader (Shanghai, China) after formazan was added. Cell viability was calculated as $\left(\mathrm{OD}_{\text {Experiment }}-\mathrm{OD}_{\text {Blank }} / \mathrm{OD}_{\text {Control }}-\mathrm{OD}_{\text {Blank }}\right) \times 100 \%$.

RNA extraction and reverse transcription. RNA extraction was performed according to t Ultrapure RNA Kit protocol. Briefly, cells were lysed in lysis buffer for $5 \mathrm{~min}$ at room temperature, followed by vigorous shaking for $15 \mathrm{sec}$ after mixing with chloroform. The mixture was then centrifuged at $13,523 \mathrm{x}$ g for $5 \mathrm{~min}$ after thorough mixing with $70 \%$ ethanol and loaded onto an adsorption column. RNA was adsorbed onto the column after samples were centrifuged at $13,523 \mathrm{x} \mathrm{g}$ for 1 min. RNA was eluted from adsorption columns using elution buffer after washing with designated wash buffer.

Reverse transcription and real-time quantitative polymerase chain reaction $(q P C R)$. Reverse transcription and $\mathrm{QPCR}$ were performed according to the Super TaqMan OneStep RT-qPCR 
Kit protocol. Primers used were as follows: IL-1 $\beta$ : Forward, 5'-ATA AGCCCACTCTACAGCT-3' and reverse, 5'-ATT GGCCCTGAAAGGAGAGA-3'; IL-2: Forward, 5'-GTC CAAGGACACAGGCTTCTT-3' and reverse, 5'-AAATTT TGGCTGGTGCCAAGG-3'; IL-6: Forward, 5'-GGCTAC GAGTGGGATACTG-3' and reverse, 5'-GGCTGGAAGGAG AAGATG-3'; Bcl-2: Forward, 5'-TGGCCTTCTTTGAGT TCGGT-3' and reverse, 5'-GTTCCACAAAGGCATCCC AGC-3'; Bax: Forward, 5'-ACACCTGAGCTGACCTTGGA-3' and reverse, 5'-AGTTCATCGCCAATTCGCCT-3'; TNF- $\alpha$ : Forward, 5'-CAGAGGGAAGAGTTCCCCAG-3' and reverse, 5'-CCTTGGTCTGGTAGGAGACG-3'. Reaction mixtures were prepared as recommended by the protocol, and the PCR cycle was set as follows: Reverse transcription at $45^{\circ} \mathrm{C}$ for $20 \mathrm{~min}$, predegeneration at $95^{\circ} \mathrm{C}$ for $5 \mathrm{~min}$, and degeneration at $95^{\circ} \mathrm{C}$ for $15 \mathrm{sec}$ with extension at $60^{\circ} \mathrm{C}$ for $45 \mathrm{sec}$ repeated for 45 cycles. Relative gene expression was determined using the $2^{-\Delta \Delta \mathrm{Cq}}$ method (13). GAPDH was used as an internal reference, and the quantified results for each target gene were normalized to GAPDH. Each experiment was repeated three times.

Western blot analysis. Cells in each group were first cultured and grouped as described above, and then lysed with lysis buffer [50 mM Tris (pH, 8.1), 1\% SDS and protease inhibitor cocktail, phosphatase inhibitor cocktail] for $30 \mathrm{~min}$ on ice after washing with sterile PBS. The supernatant was collected after centrifugation at $13,523 \mathrm{xg}$ for $10 \mathrm{~min}$, and the protein concentration was determined using a BCA assay. Protein samples $(60 \mu \mathrm{g})$ from each group were separated using $10 \%$ SDS-PAGE electrophoresis, and transferred onto $0.22-\mu \mathrm{m}$ nitrocellulose membranes using the Trans-Blot Turbo system (Bio-Rad). Membranes were incubated with $5 \%$ skim milk, and then incubated with primary antibodies (dilution 1:1,000) at $4^{\circ} \mathrm{C}$ overnight followed by incubation with secondary antibodies (dilution 1:5,000) at room temperature for $1 \mathrm{~h}$. Chemiluminiscence was performed using ECL reagents to detect expression levels of the target proteins. The gray values of bands were quantified using Scion Image software (version 4.0.3.2; Scion Corp., Frederick, MD, USA) and normalized to GAPDH. Each experiment was independently repeated three times.

Immunofluorescence experiments. Cells were cultured and grouped as described above. Phalloidin staining was performed according to the protocol, and cells were seeded onto a confocal plate at a concentration of $1 \times 10^{5}$ and cultured for $24 \mathrm{~h}$. Cells were fixed with $4 \%$ formaldehyde at room temperature for $10 \mathrm{~min}$, and then permeabilized with $0.5 \%$ Triton X-100 for $5 \mathrm{~min}$ at room temperature. Cells were stained with phalloidin staining buffer for $30 \mathrm{~min}$ and re-stained with DAPI for $5 \mathrm{~min}$. DAPI/PI double staining was performed according to the protocol. Cells were digested with trypsin-EDTA buffer and then stained with DAPI and PI for 10 min followed by imaging using fluorescence microscopy. Images were analyzed using Image-Pro Plus software (version 6.0; Media Cybernetics, Inc., Bethesda, MD, USA).

Flow cytometry. Cells were seeded onto a $100-\mathrm{mm}$ plate at a concentration of $1 \times 10^{6}$ cells, after being grouped and treated as described above. After treatment, cells were digested with trypsinization and washed with pre-cooled PBS. Then, the cells were incubated with propidium iodide (PI) for $15 \mathrm{~min}$ and apoptotic cells were quantified by FACScan flow cytometry (Becton Dickinson, Heidelberg, Germany).

Enzyme linked immunosorbent assay (ELISA). ELISA was performed according to the protocol for each ELISA kit. Briefly, standards and supernatants of cultured medium in each group were added into each well of a 96-well plate, and incubated overnight at $4^{\circ} \mathrm{C}$ with gentle shaking. Biotinylated detection antibodies were added into each well after sufficient washing with wash buffer and incubation for $1 \mathrm{~h}$ at room temperature. Then, each sample was incubated with HRP-streptavidin solution for $45 \mathrm{~min}$ at room temperature followed by incubation with TMB One-Step substrate reagent for $30 \mathrm{~min}$ at room temperature, OD values were measured at $450 \mathrm{~nm}$ using a SuPerMax 3100 microplate reader (Shanghai, China).

Statistical analysis. Data are shown as the mean \pm SD, and each experiment was independently repeated three times. One-way analysis of variance (ANOVA) was performed to compare differences between groups followed by Tukey's post hoc test. $\mathrm{P}<0.05$ was indicative of a statistically significant difference. GraphPad version 7 (GraphPad Software, Inc., La Jolla, CA, USA) was used to analyze the data.

\section{Results}

Effect of BRMS1 overexpression on the proliferation of HepG2 cells. Cells were divided into four groups: Controls (NC), sorafenib treatment (ST), sorafenib treatment with BRMS1 overexpression (BO) and sorafenib treatment with BRMS1 knockdown (BD). As shown in Fig. 1A, the viability of HepG2 cells in the ST, BO and BD groups were 75.3 $\pm 4.2,60.5 \pm 3.6$ and $89.3 \pm 5.4 \%$, respectively, in response to $10 \mu \mathrm{M}$ sorafenib treatment for $24 \mathrm{~h}$. Compared with the $\mathrm{NC}$ group, cell viability was significantly decreased in the ST and BO groups $(\mathrm{P}<0.05)$, while remaining unchanged in the $\mathrm{BD}$ group. Compared to the ST group, cell viability was significantly decreased in the BO group $(\mathrm{P}<0.05)$ and significantly increased in the BD group $(\mathrm{P}<0.05)$.

Immunofluorescence results are shown in Fig. 1B, illustrating that PI-stained cells in the ST and BO groups were increased compared to the $\mathrm{NC}$ and BD groups. However, there were no significant changes noted between the $\mathrm{NC}$ and BD groups. As shown in Fig. 1C, the ratios of apoptotic cells were $21.24 \pm 2.12,37.14 \pm 3.08,42.57 \pm 4.52$ and $18.32 \pm 2.20$ in the NC, ST, BO and BD groups, respectively. The proportion of apoptotic cells was significantly increased in the ST and $\mathrm{BO}$ groups $(\mathrm{P}<0.05)$ compared with the $\mathrm{NC}$ group, and was significantly decreased in the BO group compared with the ST group $(\mathrm{P}<0.05)$. These results indicate that sorafenib inhibits the proliferation of HepG2 cells by inducing apoptosis in cancer cells, and overexpression of BRMS1 may synergize with sorafenib in enhancing the effects. As shown in Fig. 1D, the expression level of BRMS1 in each group was $0.63 \pm 0.08$, $1.41 \pm 0.11,1.81 \pm 0.13$ and $0.86 \pm 0.09$. Compared with the NC group, the expression of BRMS1 was significantly increased in the ST and BO group $(\mathrm{P}<0.05)$ and significantly decreased in the $\mathrm{BD}$ group $(\mathrm{P}<0.05)$. Expression of BRMS1 was significantly increased in the $\mathrm{BO}$ group $(\mathrm{P}<0.05)$ and significantly decreased 

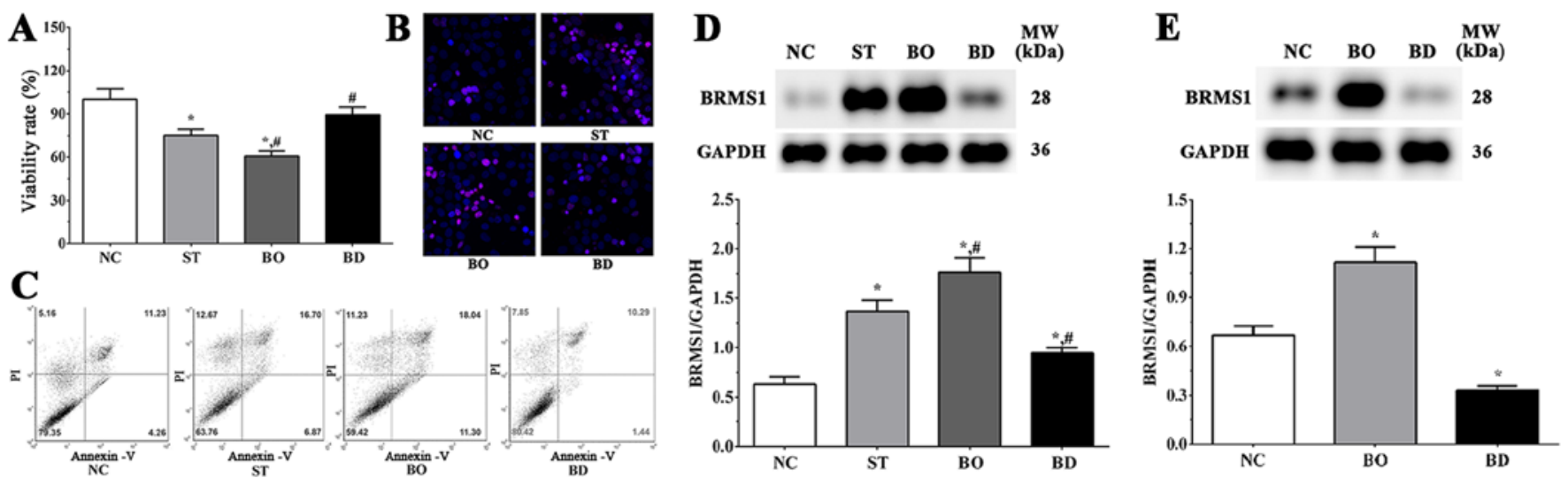

Figure 1. Effect of sorafenib on the proliferation of HepG2 cells. (A) Detection of the viability rate of HepG2 cells in each group using MTT Cell Proliferation and Cytotoxicity Assay kit. (B) Immunofluorescence results of HepG2 cells in each group using DAPI/PI staining. (C) Flow cytometry to detect apoptotic HepG2 cells in each group. (D) Detection of expression of BRMS1 in each group using western blot analysis. Groups: NC, control group; ST, sorafenib treatment group; BO, sorafenib treatment with BRMS1 overexpression group; BD, sorafenib treatment with BRMS1 knockdown group. (E) Expression of BRMS1 in each group without sorafenib treatment using western blot analysis. Groups: NC, control group; BO, BRMS1 overexpression group; BD, BRMS1 knockdown group. Data are shown as the mean \pm SEM. ${ }^{*} \mathrm{P}<0.05$ vs. the NC group. ${ }^{~} \mathrm{P}<0.05$ vs. the $\mathrm{ST}$ group. BRMS1, breast carcinoma metastasis-suppressor 1 gene.
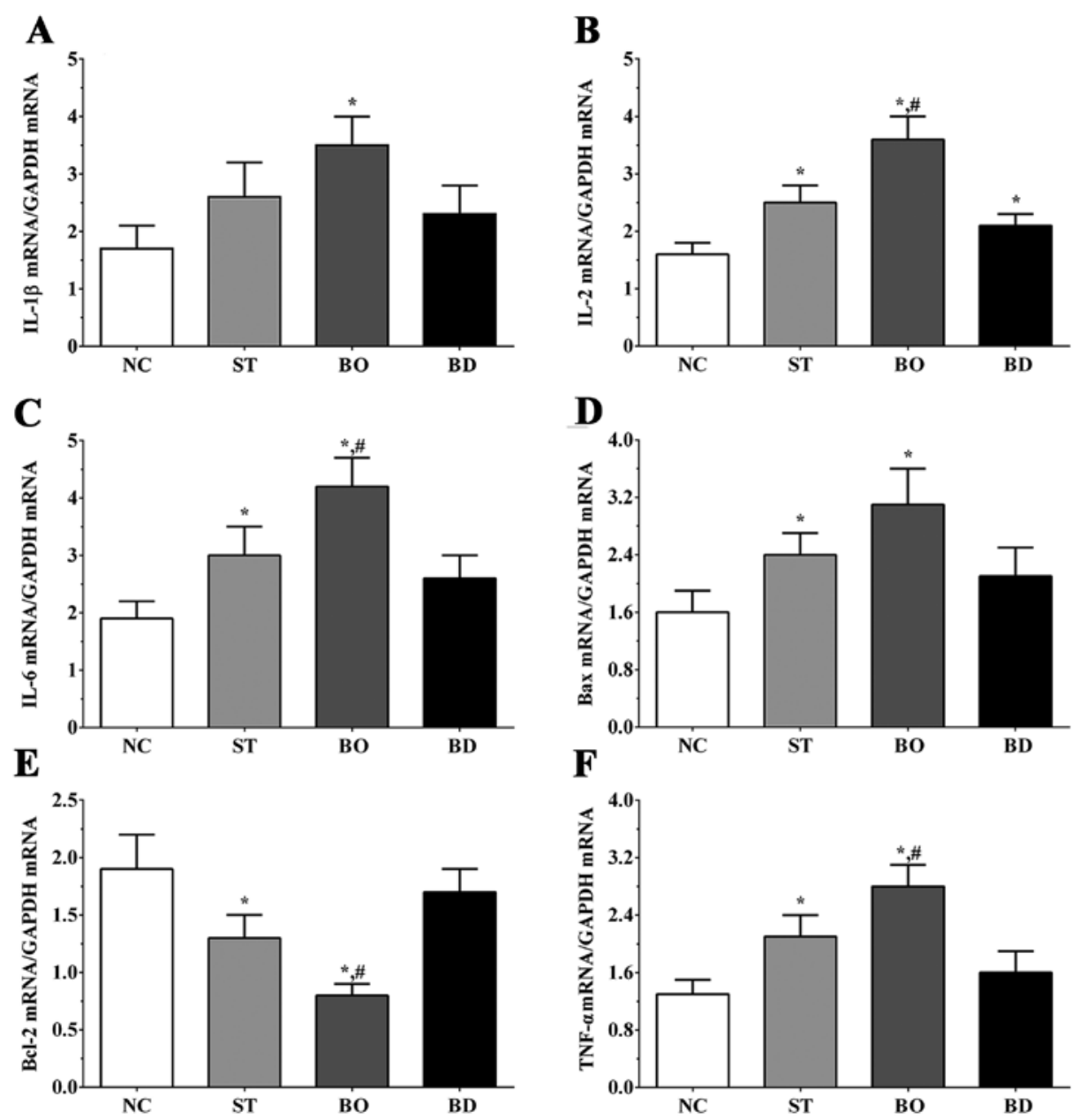

Figure 2. Expression levels of apoptosis-related genes in each group as determined by qPCR methods. Expression level of (A) IL-1 1 , (B) IL-2, (C) IL-6, (D) Bax, (E) Bcl-2 and (F) TNF- $\alpha$ in each group. Experiments were independently repeated three times. Data are shown as the mean \pm SEM. "P $<0.05$ vs. the NC group. ${ }^{\text {"P }}<0.05$ vs. the ST group. GAPDH mRNA was used as an internal control. Groups: NC, control group; ST, sorafenib treatment group; BO, sorafenib treatment with BRMS1 overexpression group; BD, sorafenib treatment with BRMS1 knockdown group. BRMS1, breast carcinoma metastasis-suppressor 1 gene.

in the $\mathrm{BD}$ group $(\mathrm{P}<0.05)$ when compared with the $\mathrm{ST}$ group. As shown in Fig. 1E, the expression levels of BRSM1 without sorafenib treatment in the normal, BRMS1 overexpression and BRMS1 knockdown groups were $0.68 \pm 0.05,1.12 \pm 0.13$ and $0.32 \pm 0.02$. Compared with the $\mathrm{NC}$ group, the expression of BRMS1 was significantly increased in the overexpression 

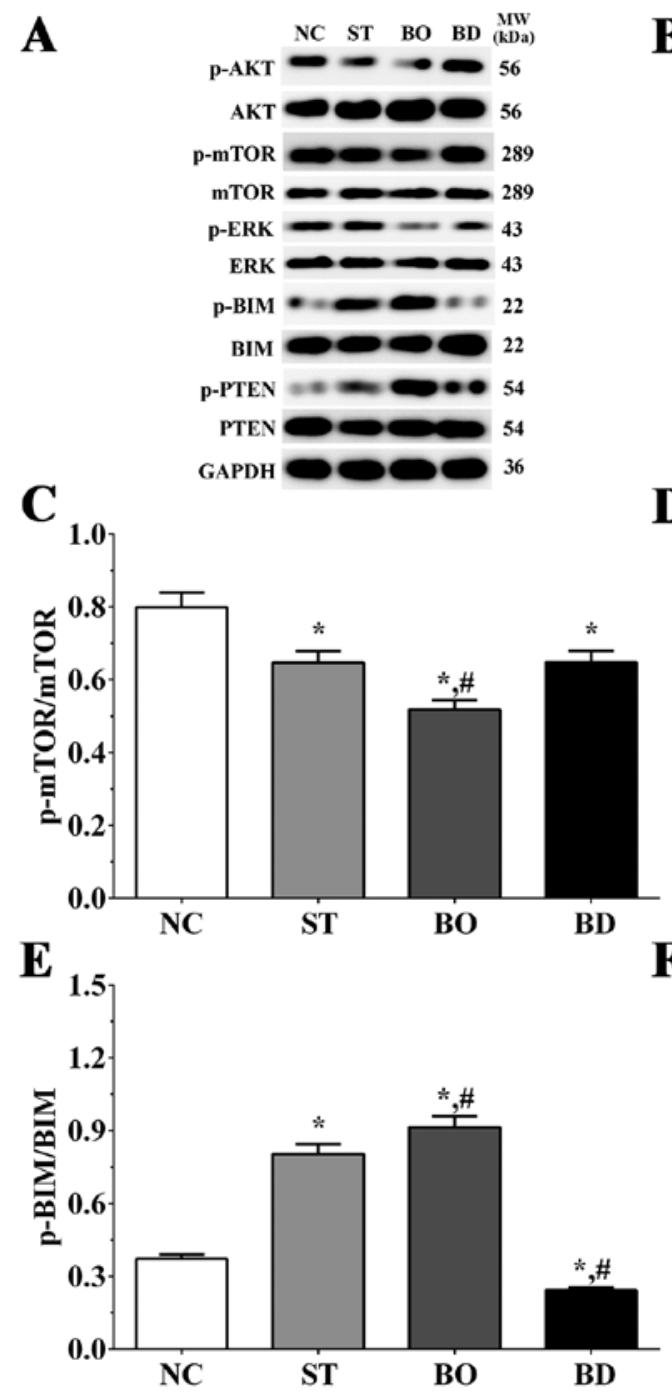

B
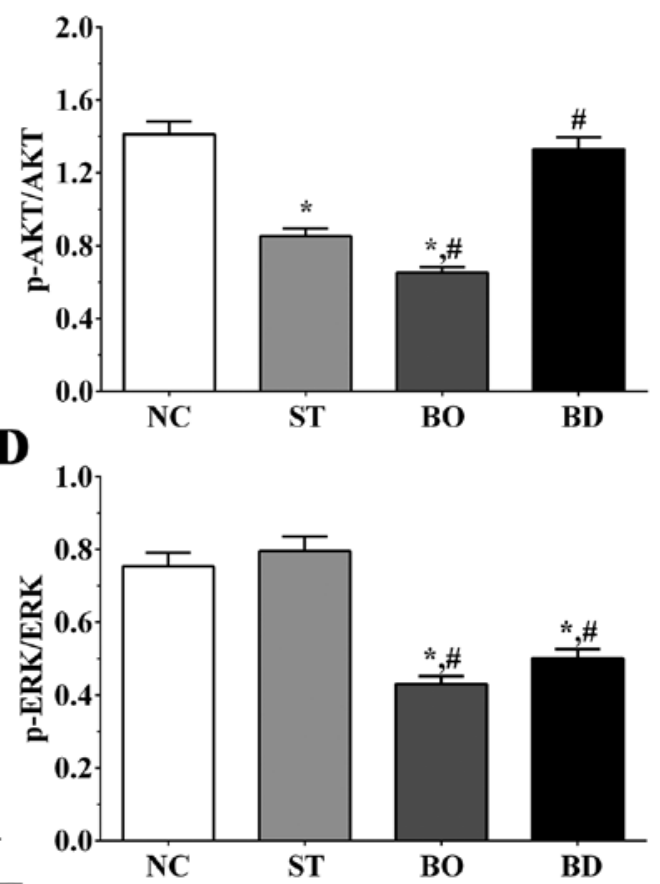

Figure 3. Expression levels of molecules in the AKT/mTOR/ERK signaling pathway. (A) The levels of p-AKT, AKT, p-mTOR, mTOR, p-ERK, ERK, p-BIM, BIM, p-PTEN and PTEN as detected using western blot analysis. (B-F) Quantitative analysis of the western blot results. Experiments were independently repeated three times. Data are shown as the mean $\pm \mathrm{SEM}$. ${ }^{*} \mathrm{P}<0.05$ vs. the NC group. ${ }^{*} \mathrm{P}<0.05$ vs. the ST group. GAPDH was used as an internal control. Groups: NC, control group; ST, sorafenib treatment group; BO, sorafenib treatment with BRMS1 overexpression group; BD, sorafenib treatment with BRMS1 knockdown group. BRMS1, breast carcinoma metastasis-suppressor 1 gene.

group $(\mathrm{P}<0.05)$ and significantly decreased in the knockdown group $(\mathrm{P}<0.05)$, indicating that the cell model was successfully constructed.

Effect of sorafenib on expression of apoptosis-related genes. As shown in Fig. 2A, expression levels of IL-1 $\beta$ in the $\mathrm{NC}, \mathrm{ST}, \mathrm{BO}$ and BD groups were $1.7 \pm 0.4,2.6 \pm 0.6$, $3.5 \pm 0.5$ and $2.3 \pm 0.5$, respectively. Expression of IL-1 $\beta$ was significantly increased in the $\mathrm{BO}$ groups when compared to that noted in the $\mathrm{NC}$ group $(\mathrm{P}<0.05)$. The expression levels of IL-2 in these groups were $1.6 \pm 0.2,2.5 \pm 0.3,3.6 \pm 0.4$ and $2.1 \pm 0.2$, respectively. As shown in Fig. 2B, IL-2 expression was significantly increased in all sorafenib-treated groups compared to the $\mathrm{NC}$ group $(\mathrm{P}<0.05)$, and was significantly increased in the $\mathrm{BO}$ group compared to the ST group $(\mathrm{P}<0.05)$. As shown in Fig. 2C, expression levels of IL-6 in these groups were $1.8 \pm 0.4,3.0 \pm 0.5,3.7 \pm 0.5$ and $2.6 \pm 0.4$. Expression of IL-6 was significantly increased in ST and BO groups compared to the $\mathrm{NC}$ group $(\mathrm{P}<0.05)$, and significantly increased in the
BO group compared to the ST group $(\mathrm{P}<0.05)$. As shown in Fig. 2D, Bax expression in these groups was 1.6 $\pm 0.3,2.4 \pm 0.3$, $3.1 \pm 0.5$ and $2.1 \pm 0.4$, respectively. The Bax expression was significantly increased in the $\mathrm{ST}$ and $\mathrm{BO}$ groups compared to the NC group $(\mathrm{P}<0.05)$. As shown in Fig. 2E, Bcl-2 expression in these groups was $1.9 \pm 0.3,1.4 \pm 0.2,0.8 \pm 0.1$ and $1.7 \pm 0.2$, respectively. Expression of Bcl-2 was significantly decreased in the ST and BO groups compared to the NC group $(\mathrm{P}<0.05)$, and was significantly decreased in the $\mathrm{BO}$ group compared to the ST group $(\mathrm{P}<0.05)$. As shown in Fig. 2F, expression levels of TNF- $\alpha$ in these groups were $1.3 \pm 0.2,2.1 \pm 0.3,2.8 \pm 0.5$ and $1.6 \pm 0.3$, respectively. TNF- $\alpha$ expression was significantly increased in the ST and BO groups compared to the $\mathrm{NC}$ group $(\mathrm{P}<0.05)$, and significantly increased in the $\mathrm{BO}$ group compared to the ST group $(\mathrm{P}<0.05)$.

Effect of sorafenib on expression levels of molecules of the PI3K/AKT/mTOR/ERK signaling pathway. As shown in Fig. $3 \mathrm{~A}$ and $\mathrm{B}$, the ratio of p-AKT/AKT was $1.41 \pm 0.07$, 

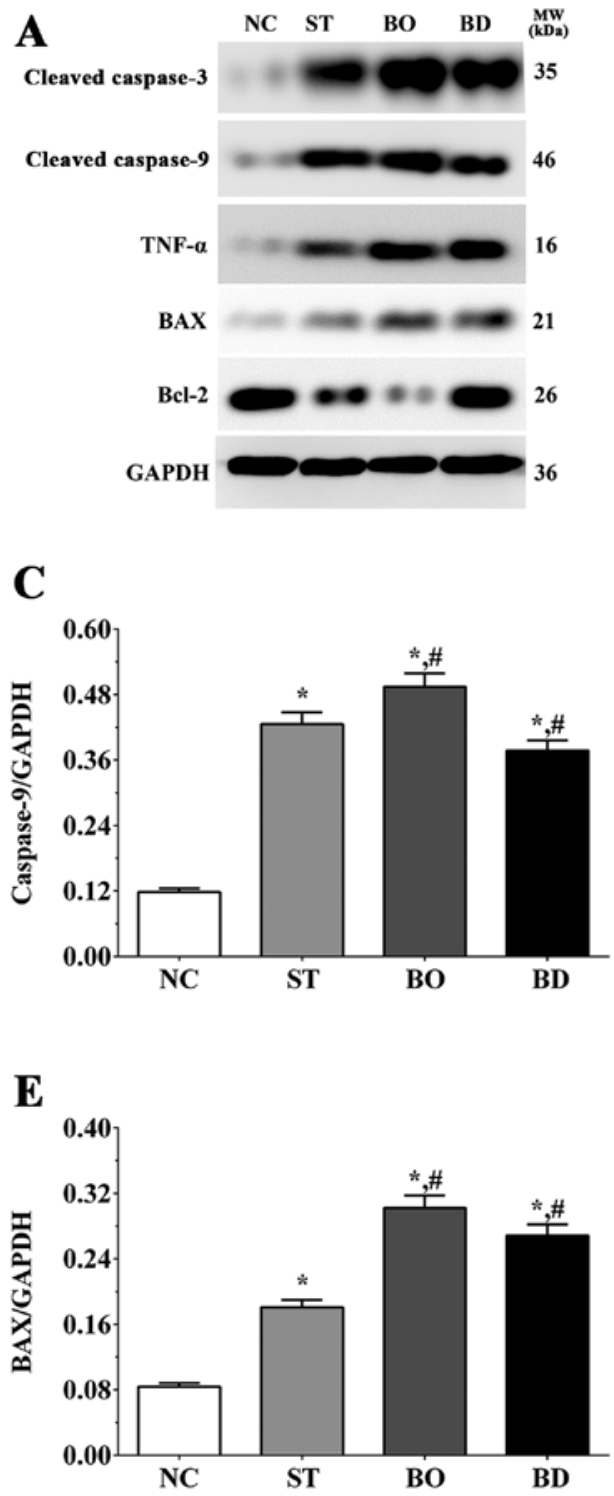

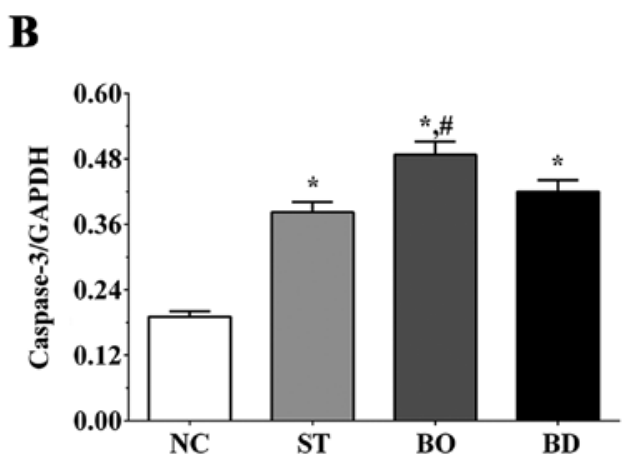

D

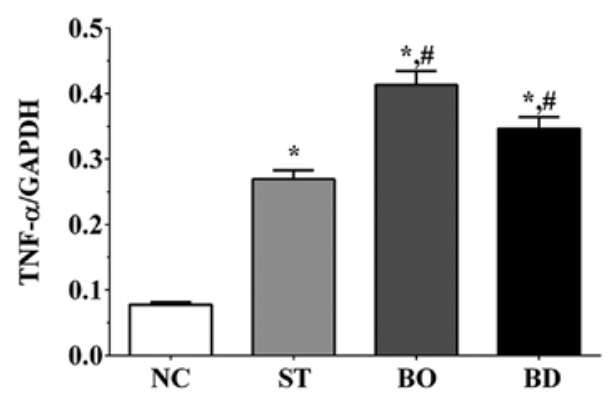

$\mathbf{F}$

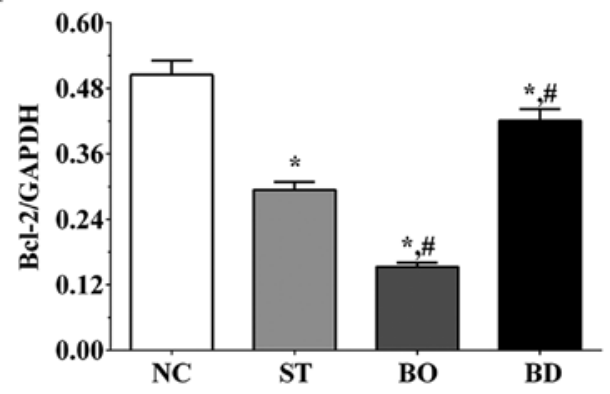

Figure 4. Expression levels of apoptosis-related proteins. (A) Expression levels of cleaved caspase-3, cleaved caspase-9, TNF- $\alpha$, Bax and Bcl-2 as detected using western blot analysis. (B-F) Quantitative analysis of the western blot results. Experiments were independently repeated three times. Data are shown as the mean \pm SEM. ${ }^{*} \mathrm{P}<0.05$ vs. the NC group. ${ }^{*} \mathrm{P}<0.05$ vs. the ST group. GAPDH was used as an internal control. Groups: NC, control group; ST, sorafenib treatment group; BO, sorafenib treatment with BRMS1 overexpression group; BD, sorafenib treatment with BRMS1 knockdown group. BRMS1, breast carcinoma metastasis-suppressor 1 gene.

$0.85 \pm 0.04,0.65 \pm 0.03$ and $1.33 \pm 0.07$ in the $\mathrm{NC}, \mathrm{ST}, \mathrm{BO}$ and $\mathrm{BD}$ groups, respectively. Compared to the $\mathrm{NC}$ group, the ratio of p-AKT/AKT was significantly decreased in the ST and $\mathrm{BO}$ groups $(\mathrm{P}<0.05)$. Furthermore, and compared to the ST group, the ratio of p-AKT/AKT was significantly decreased in the $\mathrm{BO}$ group $(\mathrm{P}<0.05)$ and significantly increased in the $\mathrm{BD}$ group $(\mathrm{P}<0.05)$. As shown in Fig. $3 \mathrm{~A}$ and $\mathrm{C}$, the ratio of $\mathrm{p}-\mathrm{mTOR} / \mathrm{mTOR}$ was $0.80 \pm 0.04,0.65 \pm 0.03,0.52 \pm 0.03$ and $0.65 \pm 0.03$ in these groups, respectively. Compared to the $\mathrm{NC}$ group, the ratio of $\mathrm{p}-\mathrm{mTOR} / \mathrm{mTOR}$ was significantly decreased in all experimental groups $(\mathrm{P}<0.05)$, and compared with the ST group, the ratio of $\mathrm{p}-\mathrm{mTOR} / \mathrm{mTOR}$ was significantly decreased in the $\mathrm{BO}$ group $(\mathrm{P}<0.05)$. As shown in Fig. 3A and D, the ratio of p-ERK/ERK was $0.75 \pm 0.04,0.80 \pm 0.03,0.43 \pm 0.02$ and $0.50 \pm 0.03$ in these groups, respectively. Compared to the NC and ST group, the ratio of $\mathrm{p}-\mathrm{ERK} / \mathrm{ERK}$ was significantly decreased in the BO and $\mathrm{BD}$ groups $(\mathrm{P}<0.05)$. As shown in Fig. $3 \mathrm{~A}$ and $\mathrm{E}$, the ratios of $\mathrm{p}-\mathrm{BIM} / \mathrm{BIM}$ was $0.37 \pm 0.02,0.80 \pm 0.04,0.91 \pm 0.05$ and $0.24 \pm 0.01$ in these groups, respectively. Compared to the $\mathrm{NC}$ group, the ratio of $\mathrm{p}-\mathrm{BIM} / \mathrm{BIM}$ was significantly increased in the ST and BO groups $(\mathrm{P}<0.05)$ and significantly decreased in $\mathrm{BD}$ group $(\mathrm{P}<0.05)$. Compared to the $\mathrm{ST}$ group, the ratio was significantly increased in the $\mathrm{BO}$ group $(\mathrm{P}<0.05)$ and significantly decreased in the BD group $(\mathrm{P}<0.05)$. As shown in Fig. $3 \mathrm{~A}$ and $\mathrm{F}$, the ratio of p-PTEN/PTEN was $0.24 \pm 0.01$, $0.59 \pm 0.03,0.87 \pm 0.04$ and $0.62 \pm 0.03$ in these groups, respectively. Compared to the NC group, the ratio of p-PTEN/PTEN was significantly increased in all experimental groups $(\mathrm{P}<0.05)$, and compared to the ST group, the ratio was significantly increased in the $\mathrm{BO}$ group $(\mathrm{P}<0.05)$.

Effect of sorafenib on the expression levels of apoptosis-related molecules. As shown in Fig. 4A and B, the expression level 
A

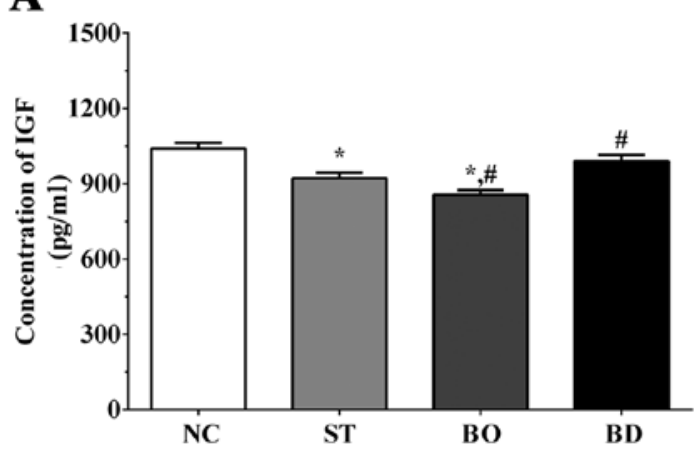

C

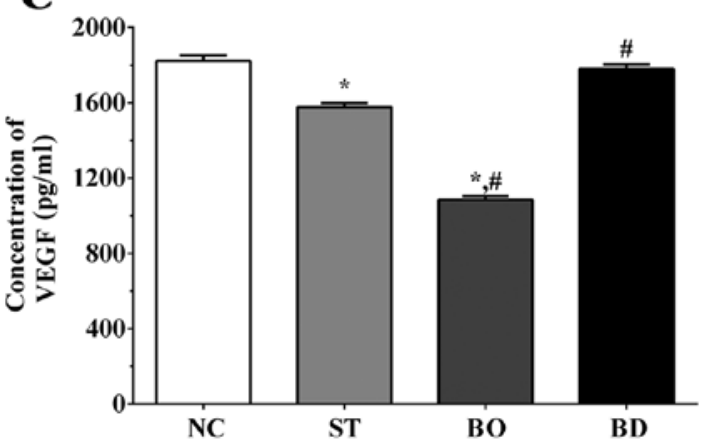

B

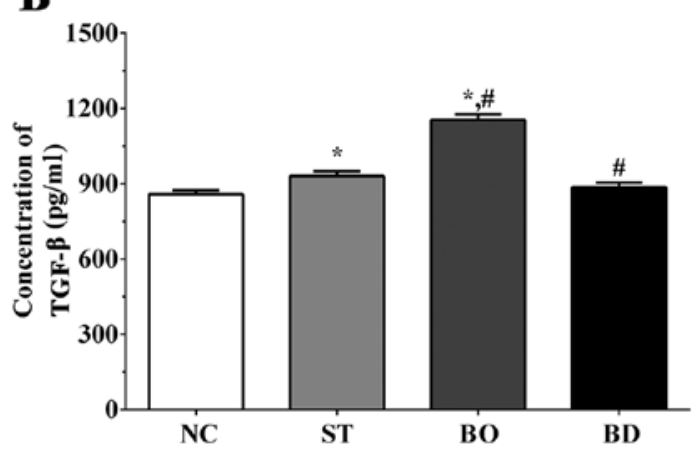

D

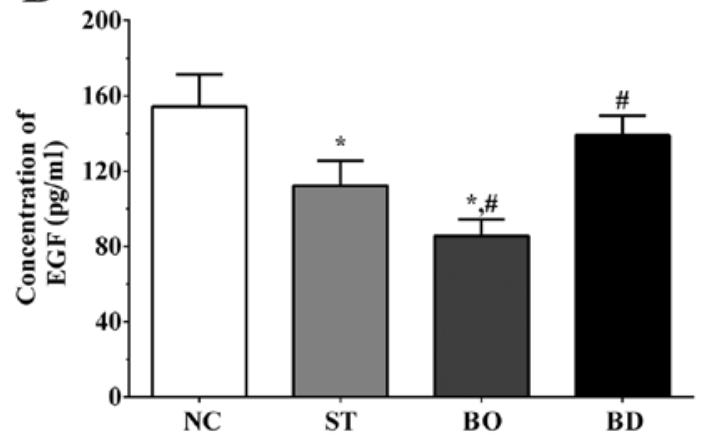

Figure 5. Angiogenesis-related cytokines in medium as detected using ELISA method. Concentrations of (A) IGF, (B) TGF- $\beta$, (C) VEGF and (D) EGF in medium. Experiments were independently repeated three times. Data are shown as the mean $\pm \mathrm{SEM}$. ${ }^{*} \mathrm{P}<0.05$ vs. the NC group. ${ }^{\#} \mathrm{P}<0.05$ vs. the $\mathrm{ST}$ group. Groups: NC, control group; ST, sorafenib treatment group; BO, sorafenib treatment with BRMS1 overexpression group; BD, sorafenib treatment with BRMS1 knockdown group. IGF, insulin-like growth factor; VEGF, vascular endothelial growth factor; EGF, epidermal growth factor; BRMS1, breast carcinoma metastasis-suppressor 1 gene.

of caspase-3 was $0.19 \pm 0.01,0.38 \pm 0.02,0.49 \pm 0.02$ and $0.42 \pm 0.02$ in the NC, ST, BO and BD groups, respectively. Compared to the NC group, expression of caspase-3 was significantly increased in all experimental groups $(\mathrm{P}<0.05)$, and compared to the ST group, expression of caspase-3 was significantly increased in the $\mathrm{BO}$ group $(\mathrm{P}<0.05)$. As shown in Fig. 4A and C, the expression level of caspase-9 was $0.12 \pm 0.01$, $0.43 \pm 0.02,0.49 \pm 0.02$ and $0.38 \pm 0.02$ in these groups, respectively. Compared to the NC group, expression of caspase-9 was significantly increased in all experimental groups $(\mathrm{P}<0.05)$, and compared with the ST group, expression of caspase-9 was significantly increased in the $\mathrm{BO}$ group $(\mathrm{P}<0.05)$ and significantly decreased in the BD group $(\mathrm{P}<0.05)$. As shown in Fig. $4 \mathrm{~A}$ and $\mathrm{D}$, the TNF- $\alpha$ expression level was $0.08 \pm 0.01$, $0.27 \pm 0.01,0.41 \pm 0.02$ and $0.35 \pm 0.02$ in these groups, respectively. Compared to the NC group, expression of TNF- $\alpha$ was significantly increased in all experimental groups $(\mathrm{P}<0.05)$, and compared to the ST group, the expression of TNF- $\alpha$ was significantly increased in the $\mathrm{BO}$ and $\mathrm{BD}$ group $(\mathrm{P}<0.05)$. As shown in Fig. 4A and E, the expression level of Bax was $0.08 \pm 0.01,0.18 \pm 0.01,0.30 \pm 0.02$ and $0.27 \pm 0.01$ in these groups, respectively. Expression changes in Bax were similar to those for TNF- $\alpha$. As shown in Fig. 4A and F, the expression level of Bcl-2 was $0.51 \pm 0.03,0.29 \pm 0.01,0.15 \pm 0.01$ and $0.42 \pm 0.02$ in these groups, respectively. Compared to the NC group, expression of Bcl-2 was significantly decreased in all the experimental groups $(\mathrm{P}<0.05)$, and compared to the ST group, expression of Bcl-2 was significantly decreased in the BO $(\mathrm{P}<0.05)$ and significantly increased in the BD group $(\mathrm{P}<0.05)$.
Effect of sorafenib on secretion of angiogenesis-related molecules. As shown in Fig. 5A, the concentration of IGF was $1,040.3 \pm 23.1,922.5 \pm 21.2,856.4 \pm 18.5$ and $990.6 \pm 23.8$ in the $\mathrm{NC}, \mathrm{ST}, \mathrm{BO}$ and BD groups, respectively. Compared to the NC group, the IGF concentration was significantly decreased in the ST and BO groups $(\mathrm{P}<0.05)$. Compared to the ST group, the concentration of IGF was significantly decreased in the $\mathrm{BO}$ group $(\mathrm{P}<0.05)$ and significantly increased in the BD group $(\mathrm{P}<0.05)$. As shown in Fig. 5B, the concentration of TGF- $\beta$ was $858.3 \pm 15.6,930.5 \pm 19.7,1154.2 \pm 21.6$ and $886.2 \pm 18.1$ in these groups, respectively. The concentration of TGF- $\beta$ was significantly increased in the ST and BO groups compared to the NC group $(\mathrm{P}<0.05)$. In addition, compared to the ST group, the concentration of TGF- $\alpha$ was significantly decreased in the $\mathrm{BD}$ group $(\mathrm{P}<0.05)$ and significantly increased in the $\mathrm{BO}$ group $(\mathrm{P}<0.05)$. As shown in Fig. 5C, the VEGF concentration was $1,823.0 \pm 28.4,1,577.2 \pm 21.4,1,085.6 \pm 18.2$ and $1,780.5 \pm 23.2$ in these groups, respectively. Compared to the NC group, the concentration of VEGF was significantly decreased in the ST and BO groups $(\mathrm{P}<0.05)$. Compared to the ST group, the concentration of VEGF was significantly decreased in the BO group $(\mathrm{P}<0.05)$, and significantly increased in BD group $(\mathrm{P}<0.05)$. As shown in Fig. 5D, the concentrations of EGF was $156.3 \pm 20.3,114.5 \pm 10.2,93.4 \pm 7.1$ and $138.9 \pm 13.2$ in these groups, respectively. Compared to the $\mathrm{NC}$ group, the concentration of VEGF was significantly decreased in the ST and BO group $(\mathrm{P}<0.05)$. Compared to the ST group, the concentration of VEGF was significantly decreased in BO group $(\mathrm{P}<0.05)$ and significantly increased in the BD group $(\mathrm{P}<0.05)$. 


\section{Discussion}

Liver cancer is the fifth most commonly occurring cancer in men and the ninth most commonly occurring cancer in women, worldwide, ranking third in cancer-related mortality and is especially common in Asia due to the presence of endemic hepatitis B viral infection. Other etiologies also contribute to the occurrence of liver cancer, including hepatitis $\mathrm{C}$ viral infection, alcoholic cirrhosis, hereditary hemochromatosis and primary biliary cirrhosis (14). Standard treatment for liver cancer differs depending on the prognosis of these patients, and most patients with early disease are not symptomatic. Liver resection is the cornerstone of surgical management for liver cancer. However, resection is only achievable in $25 \%$ of patients since tumors are often at an advanced stage at the time of diagnosis. Furthermore, post-resection local recurrence remains high, reaching $50 \%$ at 5 years (15). Sorafenib was approved for the treatment for liver cancer in Europe and in the USA in 2007 (16), and remains the only agent approved to treat systemic liver cancer.

The effect of breast carcinoma metastasis-suppressor 1 gene (BRMS1) on cell invasion and metastasis has been demonstrated in multiple cell types. However, the effect of BRMS1 on the proliferation of cancer cells remains unclear, as few studies have focused on the effect of BRMS1 on the proliferation of cancer cells. BRMS1 has been shown to inhibit the proliferation of breast cancer (17), non-small cell lung cancer (18) and forestomach carcinoma (19). In the present study, a cell model of BRMS1 overexpression and knockdown was first established. We observed that overexpression of BRMS1 enhanced the inhibitory effect of sorafenib on the proliferation of a hepatoma carcinoma cell line using MTT assay and immunofluorescence by disrupting the normal structure of hepatoma carcinoma cells. It was also found that sorafenib inhibited activation of the PI3K/AKT/mTOR signaling pathway, further inducing apoptosis via BIM, Bax, Bak, Bcl-2 and caspase enzymes. In addition, we observed activation of the immune response in response to sorafenib treatment. Expression of key factors in angiogenesis and cancer development were also inhibited after sorafenib treatment. BRMS1 overexpression enhanced the antitumor effects of sorafenib, while BRMS1 knockdown attenuated these effects. Thus, BRMS1 synergizes with sorafenib in regards to its effects on hepatoma carcinoma cells, potentially representing a novel therapeutic strategy.

Mast cells (MCs) are immune cells derived from stem cells that migrate and mature close to epithelial cells. MCs also participate in late-phase responses via releasing a variety of cytokines (TNF, IL-1 $\beta$, IL-2 and IL-6), and induce Th2 cell responses (20). IL-1 $\beta$ could affect all innate immune cells, acting as a pro-inflammatory cytokine. A previous study found that IL- $1 \beta$ activates MCs, further aggregating the FceRI receptor, followed by secretion of biologically active compounds (21). In addition, IL-1 $\beta$ induces expression of TNF- $\alpha$ in innate immune cells, including MCs and macrophages. IL-1 $\beta$ also induces expression of TNF- $\alpha$ via blocking the combination of IL-1 $\beta$ and IL-37 (22). IL-2 is a helical cytokine primarily produced by activated $\mathrm{T}$ cells that promotes lymphocytes, macrophages and NK cells (23). IL-2 binds with IL-2 receptor in T cells, further activating Janus kinase (JAK)/signal transducer and activator of transcription (STAT) pathways and mitogen-activated protein kinase (MAPK) and phosphoinositide 3-kinase signaling (PI3K) pathways, resulting in transcription of pro-inflammatory cytokines, as well as survival and cell cycle genes (24). Thus, IL-2 is considered a lymphocyte-activating and immune-stimulating factor. IL-6 is also an important cytokine in the immune response process. IL-6 is primarily produced by monocytes and $\mathrm{T}$ cells, but also epithelial cells (25). And in the present study, sorafenib treatment was found to significantly increase the expression of IL-1 $\beta$, IL-2 and IL-6 in HepG2 cells, indicating that sorafenib treatment activates the inflammatory response process in liver cancer cells, further inducing the apoptosis process. Moreover, BRMS1 overexpression was found to enhance the effect of sorafenib, while knockdown of BRMS1 reduced the effect of sorafenib. The change in the expression of pro-inflammatory cytokines further induces the change in expression of downstream molecules, leading to the change in multiple physiological processes. IL-6 promotes the development of Th17 cells via combination with TGF- $\beta$, inhibits the differentiation of Tregs induced by TGF- $\beta$, and plays an important role in the pathogenesis of chronic inflammatory disease. IL-6 not only participates in cancer-related inflammation but also plays a crucial role in DNA damage repair, proliferation, metastasis, angiogenesis and metabolic remodeling (26).

Activation of apoptosis is also an important step in the treatment of cancer. Bcl-2 was first identified through chromosomal mapping in follicular lymphoma (27). Decreased expression of pro-apoptotic proteins of the Bcl-2 family is commonly seen in cancer with increased expression of pro-survival proteins. Bcl-2 was found to increase the development of cancer by resisting cell death (28). Bcl-2 is also important for embryogenesis, and Bcl-2-deficient mice exhibit growth retardation, premature greying, and apoptotic involution of spleen/thymus, succumbing to death via polycystic kidney disease with inhibition of cellular differentiation (29). Bax and Bak are pro-apoptotic molecules in the Bcl-2 family that contain membrane anchoring C-terminal tails. Bax and Bak usually exist in dynamic equilibrium between the cytosol and membrane and are constitutively translocated to the cytosol by pro-survival Bcl-2 proteins. In the absence of Bcl-2, Bax and Bak localize to the membrane. Activation of Bax/Bak is mediated by BH3-only proteins, including BIM, tBID and PUMA, which directly interact with Bax/Bak to trigger conformational changes (30). Tumor necrosis factor $\alpha$ (TNF- $\alpha$ ) is a major pro-inflammatory cytokine that participates in multiple inflammatory pathologies and is produced by macrophages, endothelial cells, fibroblasts and T lymphocytes (31). TNF- $\alpha$ binds with TNFR1, leading to conformational changes that activate TNF receptor type-1-associated death domain protein, the adaptor protein of TNF- $\alpha$, resulting in activation of NF- $\kappa$ B, MAPK and apoptotic signaling pathways. In a pulmonary sarcoidosis model, macrophages were found to spontaneously produce TNF- $\alpha$ in excess quantities, as well as IL-1 $\beta$, IL-2, IL-6 and IL-10, leading to the formation of non-caseating granulomas (32). Furthermore, secretion of cytokines induced by TNF- $\alpha$ are especially predominant in progressive disease. In the present study, we found that the expression of pro-apoptosis molecules TNF- $\alpha$ and Bax was increased, while the expression 
of anti-apoptosis molecule $\mathrm{Bcl}-2$ was decreased at the gene and protein levels. This result indicated that sorafenib could increase the apoptosis process in liver cancer cells, and this phenomenon might be a consequence of the activation of the inflammatory process. Moreover, activation of apoptosis was enhanced by overexpression of BRMS1, while knockdown of the expression of BRMS1 reduced the effect of sorafenib.

The PI3K/AKT/mTOR signaling pathway performs an important role in the regulation of cellular metabolism, growth and survival, and dysfunction of PI3K/AKT/mTOR is commonly observed in human malignancies including renal cell carcinoma, breast cancer and neuroendocrine tumors (33). As a downstream molecule of PI3K/AKT signaling, mTOR is a $289-\mathrm{kDa}$ serine/threonine kinase that contains two large multiprotein complexes, mTORC1 and mTORC2. mTORC1 activates eukaryotic initiation factor 4E (eIF4E) binding protein 1 (p-4E-BP1) via phosphorylation, promoting dissociation of 4E-BP1 and eIF4E and subsequent eIF4E-dependent protein synthesis. AKT promotes the activation of mTOR via inhibiting phosphorylation of tuberous sclerosis complex (TSC) proteins $1 / 2$, an inhibitor of mTOR. PI3K/AKT signaling is negatively regulated by PTEN (tumor suppressor phosphatase and tensin homolog), which converts the active form of PIP3 into inactive PIP2, impairing activation of the AKT signaling pathway (34). Bim is another molecule downstream of AKT, and is an essential initiator of the apoptotic response. During the last decade, BIM was considered a critical pro-apoptotic protein for initiating the intrinsic apoptosis pathway (35). Downregulation of Bim caused by various signaling pathways may lead to tumor metastasis. Bim along with tBid and Puma, directly activate Bax/Bak, and once activated, Bax and Bak oligomers induce permeabilization of the mitochondrial outer membrane (MOM), leading to the release of cytochrome $c$, further binding with apoptotic protease-activating factor 1 (Apaf-1), and initiating the apoptotic cascade (36). Thus, we speculated that the activation of the inflammatory and apoptosis processes may be mediated by inhibition of the PI3K/AKT/mTOR/ERK signaling pathway. Furthermore, activation of PTEN was also increased after sorafenib treatment, performing an antitumor role. In addition, overexpression of BRMS1 enhanced this process. The activation of the PI3K/AKT/mTOR/ERK signaling pathway would further induce activation of the apoptosis and inflammatory response, leading to the apoptosis of liver cancer cells, ensuring an antitumor effect.

IGF is a critical molecule for angiopoiesis, and the main function of IGF in liver physiology includes organ development, growth and regeneration (37). Molecules in the IGF system are generally hepato-protective, playing an important role in hormonal and metabolic effects (38). In liver cancer patients, the concentrations of IGF in serum samples are significantly reduced compared to healthy controls. Additionally, in virus-associated liver cancer, patients also exhibit greater IGF levels than in non-infected liver cancer patients (39). Reduced IGF levels in serum sample are also correlated with advanced progression and poor overall survival. TGF- $\beta$ is a proliferation inhibiting cytokine and a tumor-suppressor factor (40). TGF- $\beta$ reduces the progression and metastasis of advanced cancer. However in latter stages of disease, TGF- $\beta$ becomes an oncogenic factor via inducing angiogenesis, invasion and immunosuppression (41). Vascular endothelial growth factor $\alpha$ (VEGF- $\alpha$ ) was firstly isolated by Ferrara's group, and was demonstrated to perform an important role in angiogenesis in a mouse model of VEGF haplo-insufficiency (42). Animal experiments identified that inhibition of VEGF- $\alpha$ reduces the growth and vascular density of tumor tissues. Furthermore, expression of VEGF- $\alpha$ is regulated by multiple factors including hypoxia, signal transducers and activators of transcription, NO gradient, microRNAs, and other factors (43). Using ELISA assay, we found that the secretion of pro-angiogenesis- and pro-proliferation-related cytokines in cultured medium was inhibited after sorafenib treatment, and overexpression of BRMS1 enhanced this trend while knockdown of BRMS1 reduced this trend. The inhibitory function in angiogenesis and proliferation further inducing the apoptosis of liver cancer cells would induce the release of inflammatory cytokines in a feedback way, further inhibiting the release of angiogenesis and proliferation cytokines.

In the present study, a model of BRMS1 overexpression and knockdown was established in HepG2 cells, demonstrating that sorafenib inhibited the proliferation in these cells. In addition, sorafenib increased the expression of apoptosis-related molecules in the HepG 2 cells at both the gene and protein levels. Next, we observed that the inflammatory response and secretion of angiogenic factors were inhibited in response to sorafenib treatment. We further demonstrated that these effects might be mediated by inhibition of the PI3K/AKT/mTOR/ERK signaling pathway. Overexpression of BRMS1 enhanced the treatment effect of sorafenib while knockdown of BRMS1 attenuated this effect, potentially representing a novel therapeutic strategy for liver cancer. However, more experiments concerning the phenotype of cells and detailed molecular changes are helpful for us to explore the possible mechanism, and clinical trials on a large scale are helpful for us to apply these findings into the treatment of cancers.

\section{Acknowledgements}

Not applicable.

\section{Funding}

The present study was supported by the Tianjin Science and Technology Project (no. 16ZXHLSY00120).

\section{Availability of data and materials}

The datasets used and/or analyzed during the current study are available from the corresponding author on reasonable request.

\section{Authors' contributions}

JJ, YG and YL performed the experiment of this manuscript. $\mathrm{XY}$ performed the flow cytometric analysis and wrote the manuscript. ZW and SS designed the present study and revised the manuscript. All authors read and approved the manuscript and agree to be accountable for all aspects of the research in ensuring that the accuracy or integrity of any part of the work are appropriately investigated and resolved. 


\section{Ethics approval and consent to participate}

Not applicable.

\section{Patient consent for publication}

Not applicable.

\section{Competing interests}

The authors state that they have no competing interests.

\section{References}

1. Parkin DM: Global cancer statistics in the year 2000. Lancet Oncol 2: 533-543, 2001

2. Raza A and Sood GK: Hepatocellular carcinoma review: Current treatment, and evidence-based medicine. World J Gastroenterol 20: 4115-4127, 2014.

3. Keating GM: Sorafenib: A review in hepatocellular carcinoma. Target Oncol 12: 243-253, 2017.

4. Chen J, Jin R, Zhao J, Liu J, Ying H, Yan H, Zhou S, Liang Y, Huang D, Liang X, et al: Potential molecular, cellular and microenvironmental mechanism of sorafenib resistance in hepatocellular carcinoma. Cancer Lett 367: 1-11, 2015.

5. Kodura MA and Souchelnytskyi S: Breast carcinoma metastasis suppressor gene 1 (BRMS1): Update on its role as the suppressor of cancer metastases. Cancer Metastasis Rev 34: 611-618, 2015.

6. Samant RS, Seraj MJ, Saunders MM, Sakamaki TS, Shevde LA, Harms JF, Leonard TO, Goldberg SF, Budgeon L, Meehan WJ, et al: Analysis of mechanisms underlying BRMS1 suppression of metastasis. Clin Exp Metastasis 18: 683-693, 2000.

7. Qiu R, Shi H, Wang S, Leng S, Liu R, Zheng Y, Huang W, Zeng Y, Gao J, Zhang K, et al: BRMS1 coordinates with LSD1 and suppresses breast cancer cell metastasis. Am J Cancer Res 8 2030-2045, 2018.

8. Rivera J, Megías D, Navas C and Bravo J: Identification of essential sequences for cellular localization in BRMS1 metastasis suppressor. PLoS One 4: e6433, 2009.

9. Chimonidou M, Strati A, Tzitzira A, Sotiropoulou G, Malamos N, Georgoulias V and Lianidou ES: DNA methylation of tumor suppressor and metastasis suppressor genes in circulating tumor cells. Clin Chem 57: 1169-1177, 2011.

10. Hicks DG, Yoder BJ, Short S, Tarr S, Prescott N, Crowe JP, Dawson AE, Budd GT, Sizemore S, Cicek M, et al: Loss of breast cancer metastasis suppressor 1 protein expression predicts reduced disease-free survival in subsets of breast cancer patients. Clin Cancer Res 12: 6702-6708, 2006.

11. Wang T, Lander ES and Sabatini DM: Large-scale single guide RNA library construction and use for CRISPR-Cas9-based genetic screens. Cold Spring Harb Protoc 2016: pdb.top086892, 2016.

12. Witt-Kehati D, Fridkin A, Alaluf MB, Zemel R and Shlomai A: Inhibition of pMAPK14 overcomes resistance to sorafenib in hepatoma cells with hepatitis B virus. Transl Oncol 11: 511-517, 2018.

13. Al Dubayee MS, Alayed H, Almansour R, Alqaoud N, Alnamlah R, Obeid D, Alshahrani A, Zahra MM, Nasr A, Al-Bawab A and Aljada A: Differential expression of human peripheral mononuclear cells phenotype markers in type 2 diabetic patients and type 2 diabetic patients and type 2 diabetic patients on metformin. Front Endocrinol (Lausanne) 9: 537, 2018.

14. Hartke J, Johnson M and Ghabril M: The diagnosis and treatment of hepatocellular carcinoma. Semin Diagn Pathol 34: 153-159, 2017.

15. Tung-Ping Poon R, Fan ST and Wong J: Risk factors, prevention, and management of postoperative recurrence after resection of hepatocellular carcinoma. Ann Surg 232: 10-24, 2000.

16. Tzogani K, Skibeli V, Westgaard I, Dalhus M, Thoresen H, Slot KB, Damkier P, Hofland K, Borregaard J, Ersbøll J, et al: The European medicines agency approval of axitinib (Inlyta) for the treatment of advanced renal cell carcinoma after failure of prior treatment with sunitinib or a cytokine: Summary of the scientific assessment of the committee for medicinal products for human use. Oncologist 20: 196-201, 2015.
17. Hedley BD, Vaidya KS, Phadke P, MacKenzie L, Dales DW, Postenka CO, MacDonald IC and Chambers AF: BRMS1 suppresses breast cancer metastasis in multiple experimental models of metastasis by reducing solitary cell survival and inhibiting growth initiation. Clin Exp Metastasis 25: 727-740, 2008.

18. You J, He X, Ding H and Zhang T: BRMS1 regulates apoptosis in non-small cell lung cancer cells. Cell Biochem Biophys 71: 465-472, 2015

19. Guo XL, Wang YJ, Cui PL, Wang YB, Liang PX, Zhang YN and $\mathrm{Xu}$ YQ: Effect of BRMS1 expression on proliferation, migration and adhesion of mouse forestomach carcinoma. Asian Pac J Trop Med 8: 724-730, 2015

20. Toniato E, Frydas I, Robuffo I, Ronconi G, Caraffa Al, Kritas SK and Conti P: Activation and inhibition of adaptive immune response mediated by mast cells. J Biol Regul Homeost Agents 31: 543-548, 2017.

21. De Feo D, Merlini A, Brambilla E, Ottoboni L, Laterza C, Menon R, Srinivasan S, Farina C, Garcia Manteiga JM, Butti E, et al: Neural precursor cell-secreted TGF- $\beta 2$ redirects inflammatory monocyte-derived cells in CNS autoimmunity. J Clin Invest 127: 3937-3953, 2017.

22. Clark IA and Vissel B: Excess cerebral TNF causing glutamate excitotoxicity rationalizes treatment of neurodegenerative diseases and neurogenic pain by anti-TNF agents. J Neuroinflammation 13: 236, 2016.

23. Apert C, Romagnoli P and van Meerwijk JPM: IL-2 and IL-15 dependent thymic development of Foxp3-expressing regulatory T lymphocytes. Protein Cell 9: 322-332, 2018.

24. Mazumder AG, Patial V and Singh D: Mycophenolate mofetil contributes to downregulation of the hippocampal interleukin type 2 and $1 \beta$ mediated PI3K/AKT/mTOR pathway hyperactivation and attenuates neurobehavioral comorbidities in a rat model of temporal lobe epilepsy. Brain Behav Immun 75: 84-93, 2019.

25. Yan C, Deng C, Liu X, Chen Y, Ye J, Cai R, Shen Y and Tang H: TNF- $\alpha$ induction of IL-6 in alveolar type II epithelial cells: Contributions of JNK/c-Jun/AP-1 element, C/EBPd/C/EBP

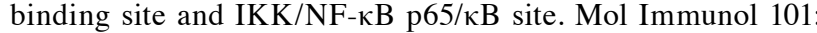
585-596, 2018.

26. Kumari N, Dwarakanath BS, Das A and Bhatt AN: Role of interleukin-6 in cancer progression and therapeutic resistance. Tumour Biol 37: 11553-11572, 2016.

27. Tsujimoto Y, Finger LR, Yunis J, Nowell PC and Croce CM: Cloning of the chromosome breakpoint of neoplastic B cells with the $t(14 ; 18)$ chromosome translocation. Science 226: 1097-1099, 1984.

28. D'Orsi B, Mateyka J and Prehn JHM: Control of mitochondrial physiology and cell death by the Bcl-2 family proteins Bax and Bok. Neurochem Int 109: 162-170, 2017.

29. Veis DJ, Sorenson CM, Shutter JR and Korsmeyer SJ: Bcl-2-deficient mice demonstrate fulminant lymphoid apoptosis, polycystic kidneys, and hypopigmented hair. Cell 75: 229-240, 1993.

30. Chipuk JE, Moldoveanu T, Llambi F, Parsons MJ and Green DR: The BCL-2 family reunion. Mol Cell 37: 299-310, 2010.

31. Sedano Muñoz R, Quera Pino R, Lubascher Correa J, Pizarro Jofré G and Simian Marín D: Evaluation of de-escalation of anti-TNF- $\alpha$ therapy in inflammatory bowel disease. Gastroenterol Hepatol 42: 133-140, 2019 (In English, Spanish).

32. Mortaz E, Sereshki HA, Abedini A, Kiani A, Mirsaeidi M, Soroush D, Garssen J, Velayati A, Redegeld FA and Adcock IM: Association of serum TNF- $\alpha$, IL- 8 and free light chain with HLA-DR B alleles expression in pulmonary and extra-pulmonary sarcoidosis. J Inflamm (Lond) 12: 21, 2015.

33. Laplante M and Sabatini DM: mTOR signaling in growth control and disease. Cell 149: 274-293, 2012.

34. Ocana A, Vera-Badillo F, Al-Mubarak M, Templeton AJ, Corrales-Sanchez V, Diez-Gonzalez L, Cuenca-Lopez MD, Seruga B, Pandiella A and Amir E: Activation of the $\mathrm{PI} 3 \mathrm{~K} / \mathrm{mTOR} / \mathrm{AKT}$ pathway and survival in solid tumors: Systematic review and meta-analysis. PLoS One 9: e95219, 2014.

35. Ersahin T, Tuncbag N and Cetin-Atalay R: The PI3K/AKT/mTOR interactive pathway. Mol Biosyst 11: 1946-1954, 2015.

36. Sionov RV, Vlahopoulos SA and Granot Z: Regulation of Bim in health and disease. Oncotarget 6: 23058-23134, 2015.

37. Chen F, Zhang L, Wu J, Huo F, Ren X, Zheng J and Pei D: HCRP-1 regulates EGFR-AKT-BIM-mediated anoikis resistance and serves as a prognostic marker in human colon cancer. Cell Death Dis 9: 1176, 2018 
38. Kasprzak A and Adamek A: The insulin-like growth factor (IGF) signaling axis and hepatitis $\mathrm{C}$ virus-associated carcinogenesis (review). Int J Oncol 41: 1919-1931, 2012.

39. Adamek A and Kasprzak A: Insulin-like growth factor (IGF) system in liver diseases. Int J Mol Sci 19: pii: E1308, 2018.

40. Wang J, Li YC, Deng M, Jiang HY, Guo LH, Zhou WJ and Ruan B: Serum insulin-like growth factor-1 and its binding protein 3 as prognostic factors for the incidence, progression, and outcome of hepatocellular carcinoma: A systematic review and meta-analysis. Oncotarget 8: 81098-81108, 2017.

41. Seoane J and Gomis RR: TGF- $\beta$ family signaling in tumor suppression and cancer progression. Cold Spring Harb Perspect Biol 9: pii: a022277, 2017.
42. Feng ZT, Yang T, Hou XQ, Wu HY, Feng JT, Ou BJ, Cai SJ, Li J and Mei ZG: Sinomenine mitigates collagen-induced arthritis mice by inhibiting angiogenesis. Biomed Pharmacother 113: 108759, 2019.

43. Xue D, Yang Y, Liu Y, Wang P, Dai Y, Liu Q, Chen L, Shen J, Ju H, Li Y and Tan Z: MicroRNA-206 attenuates the growth and angiogenesis in non-small cell lung cancer cells by blocking the 14-3-3 $\zeta /$ STAT3/HIF-1 $\alpha /$ VEGF signaling. Oncotarget 7: 79805-79813, 2016. 